\title{
Editorial Article
}

\section{Targeting eIF4F in cancer}

\section{Tingfang Yi}

Department of Biological Chemistry and Molecular Pharmacology, Harvard University Medical School, 240 Longwood Ave, Boston, 02115 USA

Corresponding author: Tingfang Yi, Department of Biological Chemistry and Molecular Pharmacology, Harvard University Medical School, 240 Longwood Ave, Boston, 02115 USA, Tel: +1-617432-3211, Fax: +1-617-432-4383; E-mail: Tingfang_yi@hms.harvard.edu

Citation: Yi T (2016) Targeting eIF4F in cancer. J Pharmaceut and Pharma Sci 2016: 1-.

Received: 26 August, 2016; Accepted: 27 August, 2016; Published: 29 August, 2016

\section{Editorial}

To overcome innate and acquired drug resistance in cancer treatment is a challenge. Translation initiation complex of eIF4F appears to be a promising target for overwhelming drug resistance in the pharmaceutical therapy against cancer $[1,2]$.

eIF4F is composed of eukaryotic translation initiation factors of cap-binding protein eIF4E, scaffolding protein eIF4G and RNA helicase eIF4A [3].eIF4F complex assembly is essential for the recruitment of mRNAs to the ribosomes during the initiation stage, the rate-limiting step in translation $[4,5]$. Many oncogenic mRNAs, which encode oncoproteins with low abundance while important for cancer cell survival, proliferation and growth, contain long and /or highly structured 5'-untranslated regions (5'-UTRs) with low translational efficiency (Figure 1) [6]. The increased eIF4F activities is critical for the upregulation of translation of oncogenic mRNAs to produce sufficient proteins to support cancer cells' apoptosis escaping, resistance to radio-/chemical therapy, uncontrolled proliferation, and aggressive metastasis [7].Therefore, interfering eIF4F activities provides unique opportunities to selectively suppress the translation of oncogenic mRNAs with low translational efficiency while leave the non-oncogenic mRNAs with high translational efficiency.

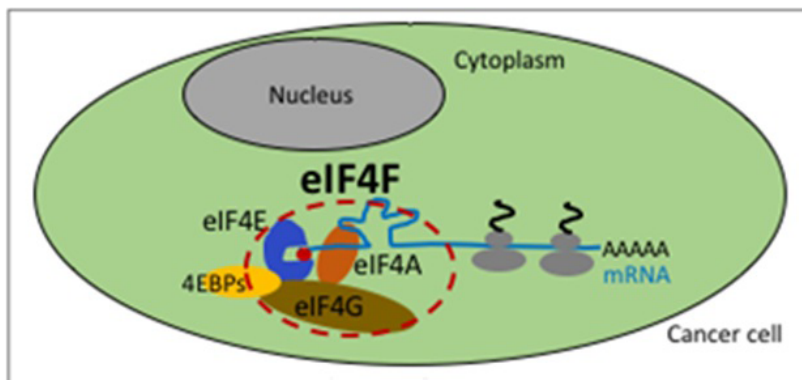

Figure 1: The elF4F complex regulates mRNA translation initiation.
Indeed, studies have found that inhibiting eIF4F complex assembly preferentially suppresses cancerous cells. The translation initiation factors eIF4E-eIF4G interaction inhibitor 4EGI-1 binds to eIF4E,induces allosteric effects to the eIF4G interacting sites on eIF4E, and therefore prevents eIF4G recruitment to eIF4E and enhances $4 \mathrm{E}-\mathrm{BP} 1$ binding to eIF4E [8]. 4E-BP1 binding to eIF4E further prevents eIF4F assembly [9]. 4EGI-1 consistently inhibits multiple cancer cell lines as well as cancer stem cells with enhanced drug resistance $[10,11]$.

Several studies have shown that targeting eIF4F can effectively overwhelm acquired drug resistance in tumors. For instance, the inhibition of eIF4F complex, either by blocking the eIF4E-eIF4G interaction or by targeting eIF4A, synergizes with drugs targeting BRAF (V600) and/or MEK to overcome drug resistance relying on multiple signaling pathways, and to kill BRAF(V600) tumor cells [12,13].

The regulation of the assembly of eIF4F complex, either by protein-protein interaction (PPI)mediation or by factor availability control, is the nexus in mediating the translation initiation apparatus. The eIF4F complex not only appears to be an indicator of both innate and acquired resistance but also is a promising therapeutic target in cancer treatment.Targeting eIF4F may overcome: 1) inherent resistance to drugs targeting one or a few oncoproteins, which is caused by cancer cell heterogeneity and/or compensation of diverse/redundant oncoproteins in a type of cancer cell; and 2) acquired resistance due to mutations after drug treatment [14].

Even though the eIF4F controlled cap-dependent translation is the major format of protein biosynthesis,internal ribosome entry site (IRES)-dependent translation produces some proteins important for cancer cell survival, proliferation and metastasis. Therefore, future pharmaceutical strategies, such as the control of both cap-dependent and IRES-dependent translation of oncogenic mRNAs, should be taken to increase the synergic effects in selectively getting rid of cancer cells and eradicating cancer stem cells. 


\section{References}

1. Boussemart L, Malka-Mahieu H, Girault I, Allard D, Hemmingsson O, et al. (2014) elF4F is a nexus of resistance to anti-BRAF and anti-MEK cancer therapies. Nature 513: 105-109.

2. Marintchev A, Wagner G (2004) Translation initiation: structures, mechanisms and evolution. Quarterly reviews of biophysics 37: 197-284.

3. Wolfe AL, Singh K, Zhong Y, Drewe P, Rajasekhar VK, et al. (2014) RNA G-quadruplexes cause elF4A-dependent oncogene translation in cancer Nature 513: 65-70.

4. Marintchev A, Edmonds KA, Marintcheva B, Hendrickson E, Oberer M, et al. (2009) Topology and regulation of the human elF4A/4G/4H helicase complex in translation initiation. Cell 136: 447-460.

5. Pelletier J, Graff J, Ruggero D, Sonenberg N (2015) Targeting the elF4F translation initiation complex: a critical nexus for cancer development. Cancer research 75: 250-263.

6. Bhat M, Robichaud N, Hulea L, Sonenberg N, Pelletier J, et al. (2015) Targeting the translation machinery in cancer. Nature reviews Drug discovery 14: $261-278$

7. Demosthenous C, Han JJ, Stenson MJ, Maurer MJ, Wellik LE, et al. (2015) Translation initiation complex elF4F is a therapeutic target for dual mTOR kinase inhibitors in non-Hodgkin lymphoma. Oncotarget 6: 9488-9501.
8. Papadopoulos E, Jenni S, Kabha E, Takrouri KJ, Yi T, et al. (2014) Structure of the eukaryotic translation initiation factor elF4E in complex with $4 \mathrm{EGI}-1$ reveals an allosteric mechanism for dissociating elF4G. Proceedings of the National Academy of Sciences of the United States of America 111: E31873195.

9. Sekiyama N, Arthanari H, Papadopoulos E, Rodriguez-Mias RA, Wagner G, et al. (2015) Molecular mechanism of the dual activity of 4EGI-1: Dissociating elF4G from elF4E but stabilizing the binding of unphosphorylated 4E-BP1. Proceedings of the National Academy of Sciences of the United States of America 112: E4036-4045.

10. Moerke NJ, Aktas H, Chen H, Cantel S, Reibarkh MY, et al. (2007) Small-molecule inhibition of the interaction between the translation initiation factors elF4E and elF4G. Cell 128: 257-267.

11. Robert F, Roman W, Bramoulle A, Fellmann C, Roulston A, et al. (2014) Translation initiation factor elF4F modifies the dexamethasone response in multiple myeloma. Proceedings of the National Academy of Sciences of the United States of America 111: 13421-13426.

12. Siddiqui N, Sonenberg N (2015) Signalling to elF4E in cancer. Biochemical Society transactions 43:763-772.

13. Tamburini J, Green AS, Bardet V, Chapuis N, Park S, et al. (2009) Protein synthesis is resistant to rapamycin and constitutes a promising therapeutic target in acute myeloid leukemia. Blood 114: 1618-1627.

14. Yi T, Kabha E, Papadopoulos E, Wagner G (2014) 4EGI-1 targets breast cancer stem cells by selective inhibition of translation that persists in CSC maintenance, proliferation and metastasis. Oncotarget 5: 6028-6037. 